\title{
Conociendo las foicinhas líticas del poblado prehistórico de Leceia (Oeiras, Portugal)*
}

\author{
The foicinhas tools of the prehistoric settlement of Leceia (Oeiras, Portugal)
}

\author{
João Luís Cardoso ${ }^{\mathrm{a}}$ y Juan F. Gibaja ${ }^{\mathrm{b}}$
}

\section{RESUMEN}

Uno de los elementos más representativos del Neolítico Final-Calcolítico en buen parte del oeste de la Península Ibérica son las piezas bifaciales elaboradas en sílex. En el territorio portugués, estas piezas, llamadas tradicionalmente foicinhas, son ahora conocidas como "láminas foliáceas". Muchos yacimientos de este periodo son poblados fortificados, siendo el de Leceia uno de los ejemplos más conocidos. Este trabajo se centra en dichas piezas que carecen de un análisis profundo. Ello es sorprendente pues son muchos los instrumentos líticos, en general, y las láminas foliáceas, en particular, documentadas en los yacimientos de esta cronología. A lo largo del texto abordamos la información relativa a la materia prima, la tecnología, la morfología y la función de estos útiles. Ello nos ha permitido evaluar las zonas de aprovisionamiento de la población de Leceia, las posibles relaciones sociales que había establecido con otros grupos a partir del origen de ciertos tipos de sílex, su capacidad tecnológica y la función a la que se destinaron algunas de esas láminas.

\begin{abstract}
Bifacial tools made of flint are some of the most representative elements of the Late Neolithic-Chalcolithic in much of the western Iberia. In Portugal these pieces, traditionally called foicinhas, are currently known as "foliaceous blades". Many sites of this period are fortified settlements, Leceia being one of the best-known examples. Surprisingly, in spite of their abundance the lithic instruments in general, and foliaceous blades in particular, in sites of this period have
\end{abstract}

not been studied in detail. Here we address the raw material, technology, morphology, and function of these tools. This allows us to evaluate the supply areas, the possible social relations established with other groups (based on the origin of certain types of flint), the technological capacity of the inhabitants of Leceia, and the function of some of these blades.

Palabras clave: Neolítico Final-Calcolítico; Occidente de la península ibérica; Tecnología lítica; Foicinhas; Láminas foliáceas.

Key words: Late Neolithic-Chalcolithic; Western Iberia; Lithic technology; Foicinhas; Foliaceous blades.

\section{INTRODUCCIÓN}

Este trabajo pretende contribuir al conocimiento de un tipo específico de instrumento lítico que surgió en el Neolítico Final (segunda mitad del IV milenio a. C.) y llegó a usarse a lo largo de todo el Calcolítico (III milenio a. C.). Algunos arqueólogos en Portugal aún las definen como foicinhas, término acuñado por Paço y Jalhay (1945) al observar en sus filos el característico "lustre de cereal". Más recientemente, uno de nosotros (JLC), ha adoptado el término de "láminas bifaciales de contorno elipsoidal" o simplemente "láminas foliáceas", precisamente para evitar cualquier relación funcionalista establecida a priori (Cardoso 1997). En Leceia la mayoría de los soportes son lascas, pero su configura-

\footnotetext{
* El análisis funcional se ha realizado en el marco del proyecto: "La difusión del Neolítico en el Mediterráneo centro-occidental: agricultura innovaciones tecnológicas y carbono 14" (HAR2016-75201-P).

a Universidade Aberta, Lisboa; Centro de Estudos Arqueológicos do Concelho de Oeiras, Câmara Municipal de Oeiras; ICArEHB, Universidade do Algarve. Rua Silva Porto, 16, Funchalinho. 2825-834 Trafaria, Portugal. Correo e.: cardoso18@netvisao.pt https://orcid.org/0000-0003-2234-2266

b Institució Milá i Fontanals, IMF-CSIC. C/ Egipcíaques 15.08001 Barcelona, España. Correo e.: jfgibaja@imf.csic.es https://orcid-org/0000-0002-0830-3570

Recibido 3-VI-2019; aceptado 16-IX-2019.
}

Copyright: (C) 2019 CSIC. Este es un artículo de acceso abierto distribuido bajo los términos de la licencia de uso y distribución "Creative Commons Reconocimiento 4.0 Internacional" (CC BY 4.0) 
ción se acerca más a la definición de lámina por la relación longitud y anchura. En otros yacimientos se ha apostado por apelativos más neutros, como "piezas foliáceas" o "foliáceas", eludiendo el soporte a partir del cual se elaboraron (Blasco et al. 2007).

Hasta hace bien poco los estudios funcionales en contextos post-neolíticos de la Península Ibérica eran realmente escasos. Y es que desafortunadamente los arqueólogos dedicados a estos periodos no veían en ellos una vía para conocer las actividades realizadas por las comunidades del pasado. Este panorama ha ido cambiando poco a poco si nos atenemos a los artículos publicados desde 1990 (Gibaja 1999, 2002; Gibaja et al. 2004, 2012; Palomo et al. 2012; Clemente et al. 2014; Díaz del Río et al. 2014; Esteve et al. 2015; Mangado et al. 2016; Marín et al. 2017), así como a las tesis doctorales presentadas ${ }^{1}$.

En este trabajo abordamos la temática de esas láminas foliáceas en el marco de un yacimiento tan espectacular como es Leceia (Oeiras, Portugal) (Fig. 1). La selección de este yacimiento no es baladí, ya que presenta una estructura compleja en su construcción como poblado fortificado, así como distintas ocupaciones que nos permiten evaluar el utillaje lítico desde una perspectiva diacrónica.

\section{MARCO HISTÓRICO Y GEOGRÁFICO DEL POBLADO DE LECEIA}

El poblado de Leceia es conocido en el ámbito científico desde 1878, cuando el General Carlos Ribeiro, fundador de la disciplina prehistórica con base científica en Portugal, presentó en la Academia Real de las Ciencias de Lisboa una extensa y bien documentada memoria. Sin embargo, no será hasta 1983 cuando, como resultado de la destrucción inminente del área arqueológica que ocupaba este yacimiento, se iniciaron las 20 campañas arqueológicas dirigidas por João Luís Cardoso que finalizaron en 2002. La superficie excavada supera los $11.000 \mathrm{~m}^{2}$; que representa prácticamente la de todo el yacimiento. Este hecho hace de Leceia, además de la excavación más extensa realizada en Portugal sobre un poblado prehistórico, uno de los yacimientos más importantes en su género y cronología en la Europa Occidental (Cardoso 1997, 2000, 2003, 2008, 2010, 2011).

Los resultados arqueológicos obtenidos han permitido definir cinco fases constructivas, repartidas en tres

D. Marín. Las implicaciones sociales de las producciones de herramientas de trabajo en asentamientos prehistóricos complejos de principios del II milenio cal ANE en el Noreste de la Península Ibérica. Relaciones entre el uso las producciones líticas y metalúrgica. Tesis Doctoral Inédita. Universitat Autònoma de Barcelona, 2018.

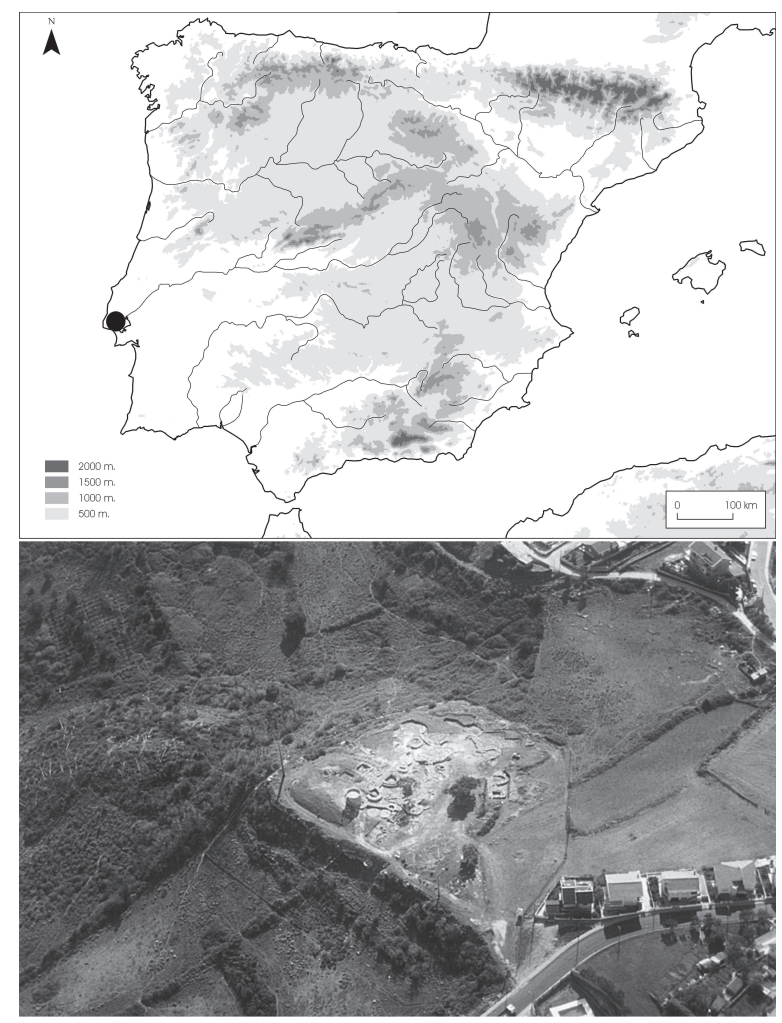

Fig. 1. Localización del poblado de Leceia (Oeiras) en la península ibérica y vista área del mismo.

fases culturales, desde el Neolítico Final (cerca del 3400-3000 a. C.) hasta el Calcolítico Pleno y Final (cerca del 2500-2250 a. C.) (Fig. 2). El yacimiento de Leceia fue ocupado durante unos mil años, quizás no de forma continuada, pero solo a inicios del Calcolítico (hacia el 2800 a. C.) se levanta una imponente fortificación, organizada en tres líneas defensivas, constituida por murallas y bastiones (Fig. 1). Se aprovecharon las estructuras calcáreas naturales a ambos lados del territorio ocupado, con más de $10 \mathrm{~m}$ de altura, para mejorar su capacidad defensiva. En el decurso de los doscientos años siguientes la fortificación fue remodelada, entrando en declive antes de mediados del III milenio a. C. De esta manera, se puede concluir que las últimas poblaciones que vivieron en el asentamiento durante el Calcolítico Pleno y Final lo hicieron literalmente entre ruinas. Sus cabañas se apoyaban sobre partes de la muralla que aún se mantenían de pie.

La construcción de esta imponente fortificación en un lugar alto y defendible, sobre el valle de Barcarena, revela las necesidades de seguridad y defensa de personas y bienes. Quizás ello fue resultado de la acumulación de excedentes derivados de una exitosa economía agro-pastoral. La relevancia de las actividades agrícolas 


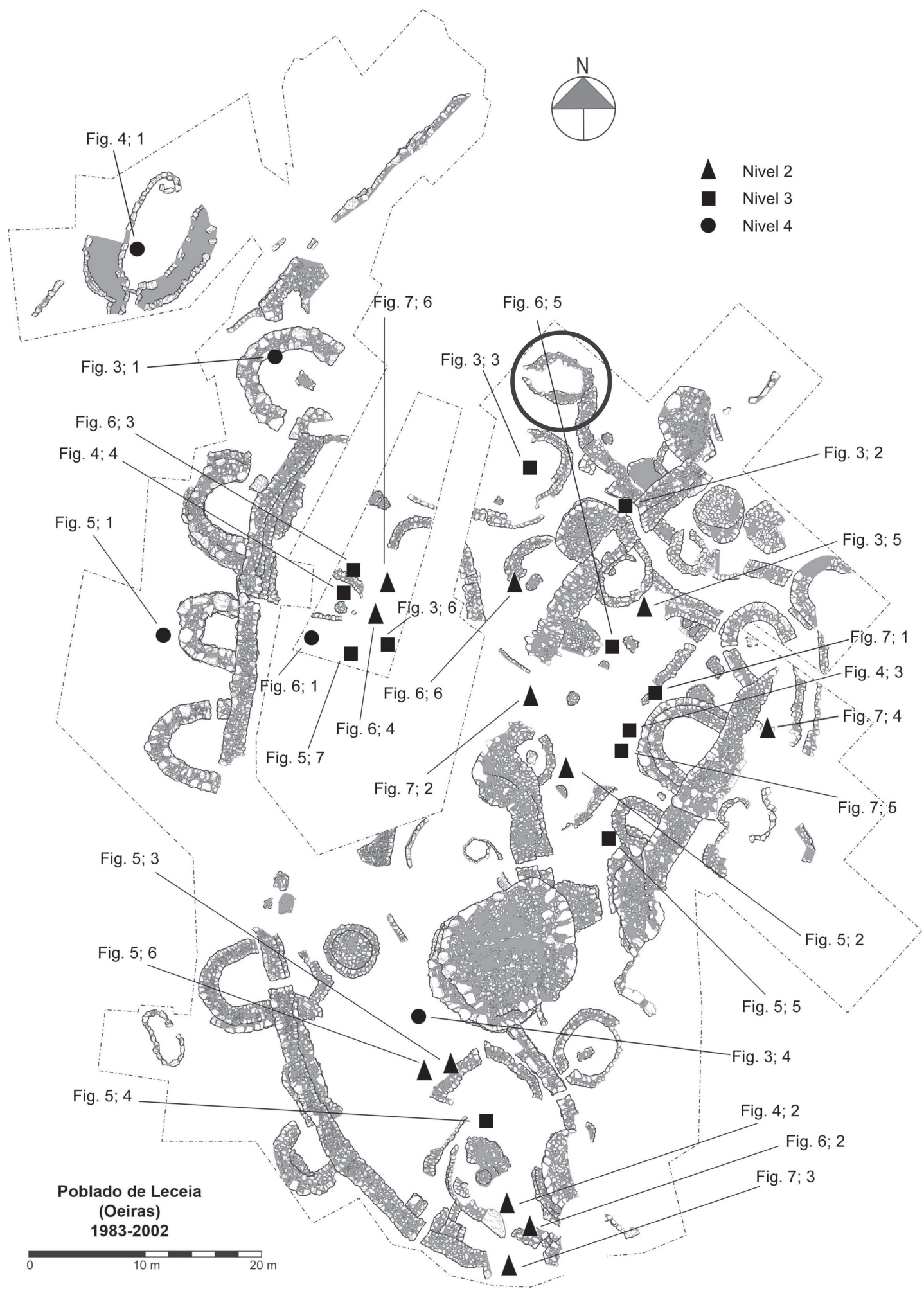

Fig. 2. Planta del poblado de Leceia (Oeiras). Localización espacial de las láminas foliáceas (Figs. 3 a 7), indicando su nivel de procedencia. Además se muestra la zona donde se hallaron en 1998 numerosos molinos y manos. 
se refleja en la existencia de numerosos molinos, dientes de hoz y azadas de piedra pulida. La cabaña ganadera está representada por abundantes restos óseos de ovinos, caprinos, suidos y bovinos. La dieta era complementada con los recursos obtenidos de la caza de venados, jabalíes, conejos, y, excepcionalmente, del oso, el caballo y el uro, así como de la recolección de moluscos y la pesca de ciertas especies que vivían cerca de línea de costa (Cardoso 1997; Cardoso y Dietry 20012002).

La inestabilidad social que caracterizó todo el III milenio a. C., al menos en la Estremadura portuguesa, vino acompañada de una creciente complejidad social. Las élites debieron gestionar las comunidades de diversos poblados fortificados como Leceia, Vila Nova de São Pedro (Azambuja) o Zambujal (Torres Vedras). En estos yacimientos también se han identificados, a lo largo de varios siglos, sucesivas fases de reconfiguración y refuerzo de las estructuras defensivas (Cardoso 2004).

Desconocemos las razones que condujeron al abandono de Leceia, pero lo cierto es que los grupos, que hasta ese momento se habían concentrado en lugares altos y en ocasiones fortificados, pasan a distribuirse en pequeñas unidades a lo largo de los vastos espacios abiertos en los territorios circundantes (Cardoso 2004).

\section{CARACTERIZACIÓN TECNO- MORFOLÓGICA DE LAS LÁMINAS FOLIÁCEAS DE LECEIA}

La primera caracterización tecno-morfológica de estas láminas se publicó en un trabajo dedicado al análisis de todo el utillaje lítico tallado (Cardoso y Martins 2013).

Consideramos láminas foliáceas aquellos artefactos adelgazados, por una o ambas caras, con retoques que suelen tener un carácter plano e invasor, pero en los que también se pueden apreciar áreas con retoques más marginales. En esta descripción entran una gran variedad de productos sobre láminas o lascas, más o menos largas y espesas, donde la talla inicial y el tipo de retoque practicado modifica enormemente el soporte original (Esta caracterización tecno-morfológica puede amplirse en S. Forenbaher 1999, J. J. Cabanilles 2008 y de A. C. Sousa²).

\subsection{La producción tecnológica}

Un total de 288 láminas foliáceas, entre enteras y fragmentadas, han sido documentadas en el poblado de

2 A. C. Sousa. O Penedo de Lexim e a sequência do Neolítico Final e Calcolítico da Península de Lisboa. Tesis Doctoral Inédita, Universidade de Lisboa, 2010.
Leceia. De éstas, 15 pertenecen al nivel 4 (Neolítico Final), 114 al nivel 3 (Calcolítico Inicial) y 159 al nivel 2 (Calcolítico Pleno/Final) (Tab. 1). En la mayoría $(88,5 \%)$ ha sido imposible determinar el tipo de soporte original, pero creemos que debieron preferirse lascas. De hecho, sólo en cinco piezas hemos podido afirmar que el soporte original era, efectivamente, una lámina: 2 del nivel 4, 1 del nivel 3 y 2 del nivel 2. Aun así, una vez acabadas, y en base a su forma, las denominamos genéricamente por consenso "láminas foliáceas".

La escasez de restos vinculados con las primeras etapas de la producción de estas piezas durante las distintas ocupaciones de Leceia, nos hacen pensar que esos trabajos iniciales se efectuaban en lugares especializados externos al poblado. Sólo las etapas finales de configuración, reparación y utilización se hacían en el interior o cerca de los espacios que ocupa el asentamiento.

Las etapas de la producción son:

Fase 1: Esbozo inicial del soporte (lasca o lámina robusta). Su fin es obtener un tamaño determinado y una morfología de contorno elipsoidal o sub-triangular (puntiaguda) (Fig. 3).

Fase 2: Preforma general de la pieza a través del retoque. Durante este proceso de adelgazamiento, realizado en ocasiones mediante presión, se emplea a menudo el tratamiento térmico. La presencia o ausencia de córtex nos permite evaluar el grado de transformación de las piezas desde su estado original. Los soportes que se han fracturado tecnológicamente suelen ser fácilmente reconocibles (Fig. 4).

Fase 3: Está representada por ejemplares plenamente configurados para ser usados. En algunos se perciben incluso probables trabajos de reparación (Fig. 5).

Las piezas halladas en las zonas de hábitat correspondientes a las primeras fases de configuración

\begin{tabular}{|l|c|c|c|c|}
\hline Soporte & Nivel 4 & Nivel 3 & Nivel 2 & Total \\
\hline Lasca & 4 & 6 & 18 & 28 \\
\hline Lámina & 2 & 1 & 2 & 5 \\
\hline Indeterminado & 9 & 107 & 139 & 255 \\
\hline $\begin{array}{l}\text { Estadio de } \\
\text { Produccion }\end{array}$ & Nivel 4 & Nivel 3 & Nivel 2 & Total \\
\hline $\begin{array}{l}\text { Fase 1 } \\
- \text { Esbozos }\end{array}$ & 3 & 5 & 10 & 18 \\
\hline $\begin{array}{l}\text { Fase 2 } \\
\text { - Preformas }\end{array}$ & 7 & 74 & 72 & 153 \\
\hline $\begin{array}{l}\text { Fase 3 } \\
\text { - Configuradas } \\
\text { Plenamente }\end{array}$ & 5 & 35 & 77 & 117 \\
\hline
\end{tabular}

Tab. 1. Soportes utilizados y estadios de producción de las láminas foliáceas del poblado de Leceia (Oeiras), en relación a su distribución estratigráfica. 

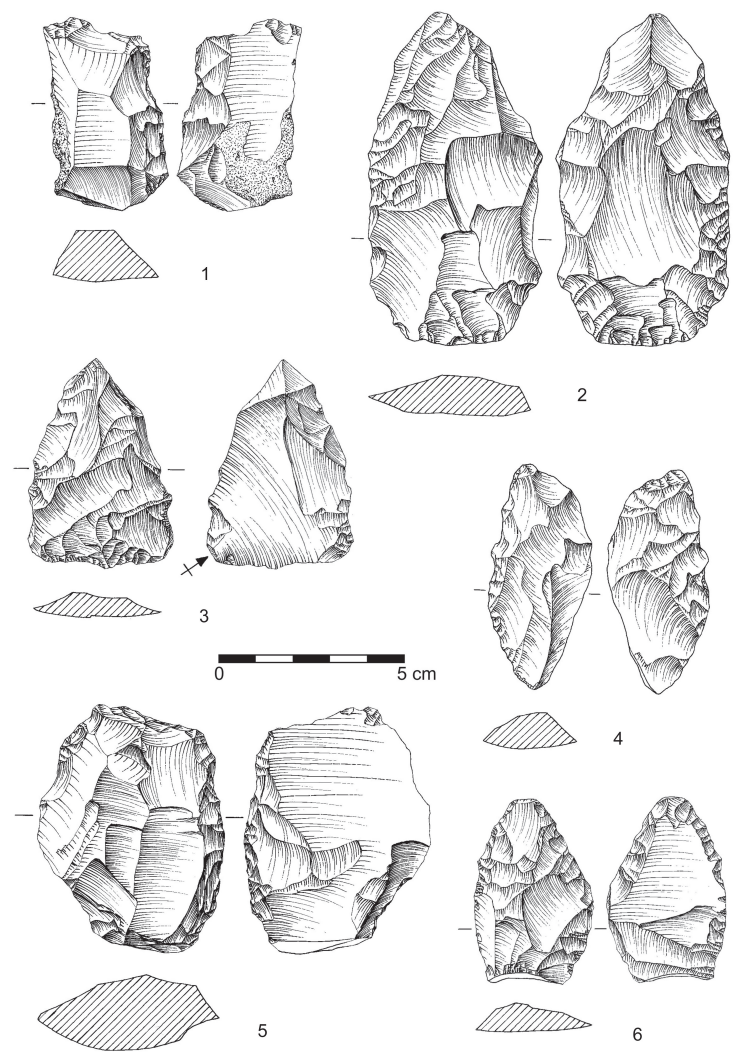

Fig. 3. Esbozos y preformas de láminas foliáceas del poblado de Leceia (Oeiras): las piezas 1 y 4 pertenecen al nivel 4; las piezas 2, 3 y 6 al nivel 3 y la pieza 5 al nivel 2 (Cardoso y Martins 2013: $473,482,483$ y 506$)$.
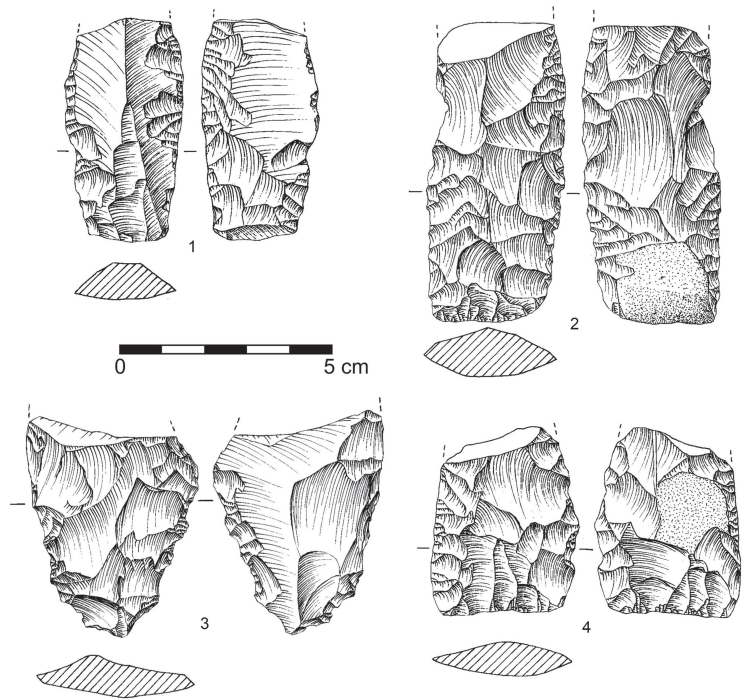

Fig. 4. Preformas del poblado de Leceia (Oeiras) pertenecientes a la fase 2 del proceso de elaboración: $1=$ nivel $4 ; 2=$ nivel $2 ; 3$ y 4 = Nivel 3 (Cardoso y Martins 2013: 473, 483, 489 y 517).
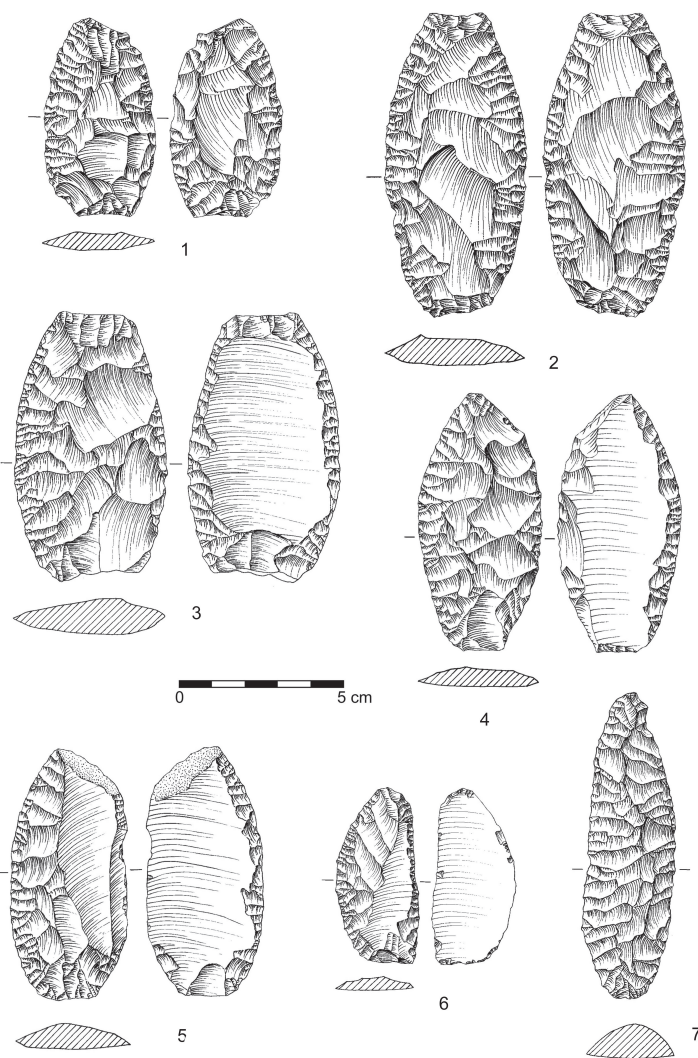

Fig. 5. Láminas foliáceas del poblado de Leceia (Oeiras) con morfología final definida por el tipo de retoque: bifacial cubriente (1 del nivel 4; 2 del nivel 2); cubriente en una de las caras y retoques invasores y marginales en la opuesta (3 del nivel 2; 4 del nivel 3); invasor en una cara y retoques marginales en la opuesta ( 5 del nivel 3 ); cubriente en una cara y sin retoque en la opuesta (6 del nivel 2; 7 del nivel 3) (Cardoso y Martins 2013: 473, 487, 489 y 513-515).

(Tab. 1). Representan el 4,4 \% en el nivel 3, el 6,3\% en el 2 y el $20 \%$ en el 4 . Este último dato debe tomarse con precaución por las escasas piezas del nivel.

Las preformas pertenecientes a la fase 2 se documentan habitualmente en el interior de la zona habitada. Su representación en el nivel 3 llega al 64,9\%, siendo algo menor en el nivel 2 y el 4 (poco más del $45 \%$ ). En la mayoría de ellas ya no existen restos de córtex: $80 \%$ en el nivel $4 ; 91,2 \%$ en el $3 ;$ y $88,1 \%$ en el 2. Finalmente, 117 piezas están plenamente configuradas (fase 3), procediendo en su mayoría del nivel 2.

\subsection{Naturaleza de la materia prima}

Todas las láminas foliáceas han estado elaboradas en sílex. Las variedades cromáticas más representadas en todos los niveles son las grisáceas, marrones, negruzcas 
y rosadas. En Monte do Castelo y Barotas, a unos 800 $\mathrm{m}$ del poblado, sería sencillo aprovisionarse de las variedades de color marrón y negro. En cambio, las de tonalidades grisáceas tendrían un origen alóctono procedente quizás de la región de Rio Maior, a unos 100 km de Leceia (Cardoso y Costa 1992; Cardoso et al. 1996). Esta determinación de las posibles fuentes de materia prima se ha basado en un análisis macroscópico y en los amplios conocimientos de uno de los autores (JLC) del territorio luso (Cardoso et al. 2018: 352, fig. 8).

Entre el Calcolítico Inicial y el Calcolítico Pleno/ Final se aprecia un cambio en el tipo de sílex en base a su coloración. Las piezas de tonos grisáceos aumentan del 26,6 \% en el nivel 3 al 35,4 \% en el 2. Simultáneamente, las de color marrón disminuyen desde el 40,5\% en el nivel 3 al 29,3\% en el 2. El incremento de variedades de sílex de procedencia alóctona durante el Calcolítico Pleno/Final, quizás responda a una apertura y contacto de la comunidad de Leceia con otras poblaciones asentadas en territorios alejados. Asimismo, la intensificación desde el Neolítico Final de la explotación de las variedades de sílex local, probablemente refleje que parte de los productos obtenidos se destinaban a su exportación. En las láminas foliáceas plenamente configuradas atribuidas a la fase 3 , se aprecia de nuevo más piezas de color grisáceo entre el Calcolítico Inicial y el Calcolítico Pleno/Final: se pasa del $14,3 \%$ en el nivel 3 , al $40,3 \%$ en el 2 . Contrariamente, las de color marrón disminuyen del 40,5\% en el nivel 3, al 29,9\% en el 2 (Tab. 2).

\begin{tabular}{|l|l|c|c|c|c|c|c|}
\hline \multicolumn{2}{|l|}{ Color Sílex } & \multicolumn{2}{|c|}{ Nivel 4 } & \multicolumn{2}{c|}{ Nivel 3 } & \multicolumn{2}{c|}{ Nivel 2 } \\
\hline \multirow{2}{*}{} & & $\begin{array}{c}\text { Fase } \\
\mathbf{1 - 2}\end{array}$ & $\begin{array}{c}\text { Fase } \\
\mathbf{3}\end{array}$ & $\begin{array}{c}\text { Fase } \\
\mathbf{1 - 2}\end{array}$ & $\begin{array}{c}\text { Fase } \\
\mathbf{3}\end{array}$ & $\begin{array}{c}\text { Fase } \\
\mathbf{1 - 2}\end{array}$ & $\begin{array}{c}\text { Fase } \\
\mathbf{3}\end{array}$ \\
\hline \multirow{2}{*}{ Gris } & Oscuro & 5 & 1 & 9 & 3 & 13 & 15 \\
\cline { 2 - 8 } & Claro & 1 & - & 12 & 2 & 16 & 22 \\
\hline \multicolumn{2}{|l|}{ TOTAL } & 6 & 1 & 21 & 5 & 29 & 37 \\
\hline \multirow{2}{*}{ Marrón } & Oscuro & - & 2 & 9 & 4 & 4 & 9 \\
\cline { 2 - 8 } & Claro & - & 2 & 23 & 12 & 20 & 34 \\
\hline \multicolumn{2}{|l|}{ TOTAL } & & 4 & 32 & 16 & 24 & 43 \\
\hline \multicolumn{2}{|l|}{ Negro } & - & & - & & 4 & 1 \\
\hline \multicolumn{2}{|l|}{ Melado } & - & & - & 1 & 1 & 1 \\
\hline Blanco & 1 & & 1 & 2 & 1 & 6 \\
\hline Rosa & 2 & & 25 & 8 & 21 & 23 \\
\hline Rojo & & & & & & 2 \\
\hline Naranja & 1 & & - & 3 & 2 & 4 \\
\hline TOTAL & 10 & 5 & 79 & 35 & 82 & 117 \\
\hline
\end{tabular}

Tab. 2. Variedades cromáticas del sílex usado en la producción de las láminas foliáceas del poblado de Leceia (Oeiras), relacionadas con las distintas fases arqueológicas.

\subsection{La configuración de las láminas foliáceas}

Las modalidades de configuración identificadas son: 1) un retoque cubriente: bifacial (Fig. 5: 1-2) o unifacial y, en ese caso, con la cara opuesta con retoques invasores y marginales (Fig. 5: 3-4) o sin retoque (Fig. 5: 6-7); y 2) Un retoque invasor bifacial en todo el perímetro, pero no en las zonas centrales, o unifacial ya sea con áreas con retoques marginales en la opuesta (Fig. 5: 5) o sin retoque.

En Leceia estas distintas formas de adelgazamiento/ retoque varían porcentualmente según su distribución estratigráfica. Las láminas foliáceas con retoque cubriente bifacial tienen una representación porcentual muy elevada en todos los niveles: $60 \%$ en el $4,48,6 \%$ en el 3 y $59,7 \%$ en el 2, pero en el nivel más antiguo, nuevamente la escasez general de piezas documentadas impide hacer valoraciones concluyentes (Tab. 3).

El segundo grupo más numeroso, ausente en el nivel 4, comprende las láminas foliáceas con retoque cubriente en una cara e invasor o marginal en la opuesta: $34,3 \%$ en el nivel 3 y $24,7 \%$ en el 2 . Según Antonio F. Carvalho (1995-1996) a menudo estas piezas han pasado por distintos estadios de reavivado. Nuestro estudio tecnológico ha identificado cinco láminas foliáceas con posibles signos de reavivado: 1 en el nivel 3 y 4 en el 2. Gracias a la presencia de melladuras sin lustre de cereal en los filos de las piezas empleadas para segar.

A veces se reconoció el uso del tratamiento térmico en la configuración inicial de estas piezas, gracias a que algunas presentaban facetas sin brillo en ambas caras. $\mathrm{Si}$ se hubiera calentado el bloque/núcleo, esas zonas opacas estarían exclusivamente en la cara dorsal. Las comunidades de Leceia controlaban perfectamente el proceso, ya que no se aprecian modificaciones térmicas por temperaturas demasiado elevadas (Terradas y Gibaja 2001). Cuando ello sucede, aparecen en la superficie craquelados, cúpulas y pátinas térmicas. Leceia presenta ciertas diferencias en el tratamiento térmico respecto al asentamiento portugués de Chibanes, donde se afirma que todas las láminas foliáceas se extrajeron de núcleos tratados térmicamente y no de soportes (Clemente et al. 2014). Los datos aquí presentados sobre el tratamiento térmico son muy parciales porque se refieren a las piezas analizadas a nivel funcional. Será necesario hacer un estudio mucho más completo para discernir si hay alguna relación con el tipo de materia prima empleada.

\subsection{Morfología de las láminas foliáceas}

La tipología específica elaborada en Leceia distingue 7 formas de láminas: 'de contorno elipsoidal' con bordes convergentes y extremidades planas, cóncavas

Trab. Prehist., 76, N. ${ }^{\circ} 2$, julio-diciembre 2019, pp. 357-370, ISSN: 0082-5638

https://doi.org/10.3989/tp.2019.12243 


\begin{tabular}{|c|c|c|c|c|c|}
\hline \multicolumn{2}{|r|}{ Tipos Láminas Foliáceas } & Nivel 4 & Nivel 3 & Nivel 2 & Total \\
\hline \multirow{6}{*}{ Elipsoidal } & Retoque bifacial cubriente & 3 & 9 & 33 & 45 \\
\hline & $\begin{array}{l}\text { Retoque cubriente en una de las caras. En la opuesta presencia } \\
\text { de retoques invasores y marginales }\end{array}$ & - & 5 & 11 & 16 \\
\hline & $\begin{array}{l}\text { Retoque cubriente en una de las caras, sin estar retocada la cara } \\
\text { opuesta }\end{array}$ & - & 1 & 1 & 2 \\
\hline & Retoque bifacial invasor & - & 2 & 6 & 8 \\
\hline & $\begin{array}{l}\text { Retoque invasor en una de las caras. En la opuesta presencia de } \\
\text { retoques marginales }\end{array}$ & - & - & 2 & 2 \\
\hline & $\begin{array}{l}\text { Retoque invasor en una de las caras, sin estar retocada la cara } \\
\text { opuesta }\end{array}$ & - & 1 & - & 1 \\
\hline \multirow{5}{*}{$\begin{array}{l}\text { En forma } \\
\text { de "D" }\end{array}$} & Retoque bifacial cubriente & - & 2 & 3 & 5 \\
\hline & $\begin{array}{l}\text { Retoque cubriente en una de las caras. En la opuesta presencia } \\
\text { de retoques invasores y marginales }\end{array}$ & - & - & 4 & 4 \\
\hline & Retoque bifacial invasor & - & - & 1 & 1 \\
\hline & $\begin{array}{l}\text { Retoque invasor en una de las caras. En la opuesta presencia de } \\
\text { retoques marginales }\end{array}$ & - & 1 & 1 & 2 \\
\hline & $\begin{array}{l}\text { Retoque invasor en una de las caras, sin estar retocada la cara } \\
\text { opuesta }\end{array}$ & 1 & - & - & 1 \\
\hline \multirow{3}{*}{$\begin{array}{l}\text { En forma } \\
\text { de creciente }\end{array}$} & Retoque bifacial cubriente & - & 2 & 3 & 5 \\
\hline & $\begin{array}{l}\text { Retoque cubriente en una de las caras. En la opuesta presencia } \\
\text { de retoques invasores y marginales }\end{array}$ & 1 & 1 & - & 2 \\
\hline & $\begin{array}{l}\text { Retoque invasor en una de las caras. En la opuesta presencia de } \\
\text { retoques marginales }\end{array}$ & - & 1 & - & 1 \\
\hline Sub-circular & Retoque bifacial cubriente & - & - & 1 & 1 \\
\hline \multirow{2}{*}{$\begin{array}{l}\text { Sub- } \\
\text { rectangular }\end{array}$} & Retoque bifacial cubriente & - & - & 1 & 1 \\
\hline & $\begin{array}{l}\text { Retoque cubriente en una de las caras. En la opuesta presencia } \\
\text { de retoques invasores y marginales }\end{array}$ & - & 1 & 1 & 2 \\
\hline \multirow{3}{*}{$\begin{array}{l}\text { Sub- } \\
\text { trapezoidal }\end{array}$} & Retoque bifacial cubriente & - & - & 3 & 3 \\
\hline & $\begin{array}{l}\text { Retoque cubriente en una de las caras. En la opuesta presencia } \\
\text { de retoques invasores y marginales }\end{array}$ & - & 1 & 1 & 2 \\
\hline & $\begin{array}{l}\text { Retoque invasor en una de las caras. En la opuesta presencia de } \\
\text { retoques marginales }\end{array}$ & - & - & 2 & 2 \\
\hline \multirow[b]{2}{*}{ Apuntada } & Retoque bifacial cubriente & - & 4 & 2 & 6 \\
\hline & $\begin{array}{l}\text { Retoque cubriente en una de las caras. En la opuesta presencia } \\
\text { de retoques invasores y marginales }\end{array}$ & - & 4 & 1 & 5 \\
\hline \multicolumn{2}{|l|}{ TOTAL } & 5 & 35 & 77 & 117 \\
\hline
\end{tabular}

Tab. 3. Morfología y tipo de retoque en las diferentes láminas foliáceas plenamente configuradas del poblado de Leceia (Oeiras), en relación a su distribución estratigráfica.

y/o convexas (Fig. 6: 1-2); 'en forma de D', con un borde rectilíneo y otro convexo (Fig. 6: 3-4); 'en forma de creciente', con un borde convexo y otro cóncavo, generalmente estrechas y alargadas, (Fig. 6: 5-6); 'sub-circulares' de menores dimensiones; 'sub-rectangulares' cuyos bordes paralelos tienen extremidades rectilíneas y contornos sub-rectangulares (Fig. 7: 1-2); 'sub-trapezoidales' con bordes paralelos o divergentes y una o ambas extremidades oblicuas (Fig. 7: 3-4); 'apuntadas' en su extremidad distal. Incluye las de morfología losángica alargada (Fig. 7: 5-6).

En Leceia las láminas foliáceas están documentadas desde el Neolítico Final, pero su representatividad aumenta considerablemente en el Calcolítico Inicial y, en especial, en el Calcolítico Pleno/Final (Tab. 3). Quizás si se hubiera excavado todo el yacimiento su número en el nivel 4 habría sido mayor. En todo caso, en el nivel 4 el $60 \%$ son láminas con retoque cubrien- 
te bifacial, el $20 \%$ tiene forma de " $\mathrm{D}$ " con retoque invasor en una de las caras, y el otro $20 \%$ son de tipo creciente con retoque cubriente en una cara e invasor o marginal en la opuesta.

En el nivel 3 dominan las láminas de tipo elipsoidal $(51,4 \%)$, seguidas por las apuntadas $(22,9 \%)$, las de forma creciente $(11,4 \%)$, las tipo "D" $(8,6 \%)$, las sub-rectangulares $(2,9 \%)$ y las de contorno sub-trapezoidal $(2,9 \%)$.

Finalmente, en el nivel 2 dominan las láminas de tipo elipsoidal $(68,9 \%)$, seguidas por las que tienen forma de "D" (11,7 \%), las sub-trapezoidales $(7,8 \%)$, las de forma creciente $(3,9 \%)$, las apuntadas $(3,9 \%)$, las sub-rectangulares $(2,6 \%)$ y las sub-circulares $(1,3 \%)$.

\subsection{Dimensión de las láminas foliáceas}

En la tabla 4 reflejamos la longitud y anchura de las láminas foliáceas plenamente configuradas. Los tamaños van desde los $30 \mathrm{~mm}$ hasta los $120 \mathrm{~mm}$. Sin

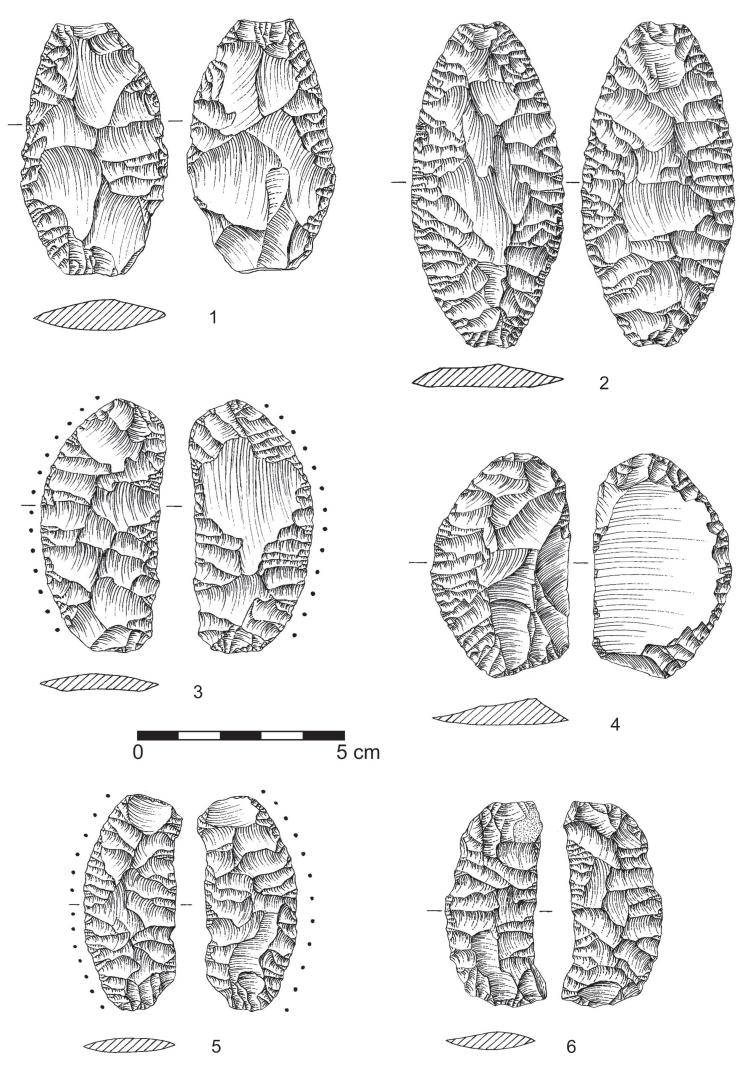

Fig. 6. Morfología de las láminas foliáceas del poblado de Leceia (Oeiras): elipsoidal (1 del nivel 4; 2 del nivel 2); en forma de " $\mathrm{D}$ " (3 del nivel 3, 4 del nivel 2); en forma creciente (5 del nivel 3: 6 del nivel 2) (Cardoso y Martins 2013: 473, 487, 489, 512, 513 y 516). entrar a valorar el de las pocas piezas del nivel 4, en el nivel 3 y el 2 el mayor porcentaje corresponde a las que tienen entre $61-70 \mathrm{~mm}(31,4 \%$ y $32,5 \%$, respectivamente). En estos dos niveles apenas hay láminas con tamaños superiores a los $90 \mathrm{~mm}$.

En cuento a la anchura, en el nivel 4 y el nivel 2 sobresalen las que tienen entre $33-36 \mathrm{~mm}(40 \% \mathrm{y}$ $31,2 \%$, respectivamente), mientras en el nivel 3 destacan las de 29-32 mm (37,1 \%). En definitiva, se aprecia una ligera tendencia a que las láminas más largas y anchas sean las del nivel 2.

\subsection{Distribución espacial de las láminas foliáceas}

En el nivel 3 se evidencian dos concentraciones de artefactos. La primera tiene un nítido carácter funcional, pues se localiza en el espacio exterior de la tercera línea defensiva, donde se concentran las unidades habitacionales del Calcolítico Inicial. La segunda resulta de la mayor potencia del nivel 3 entre la prime-

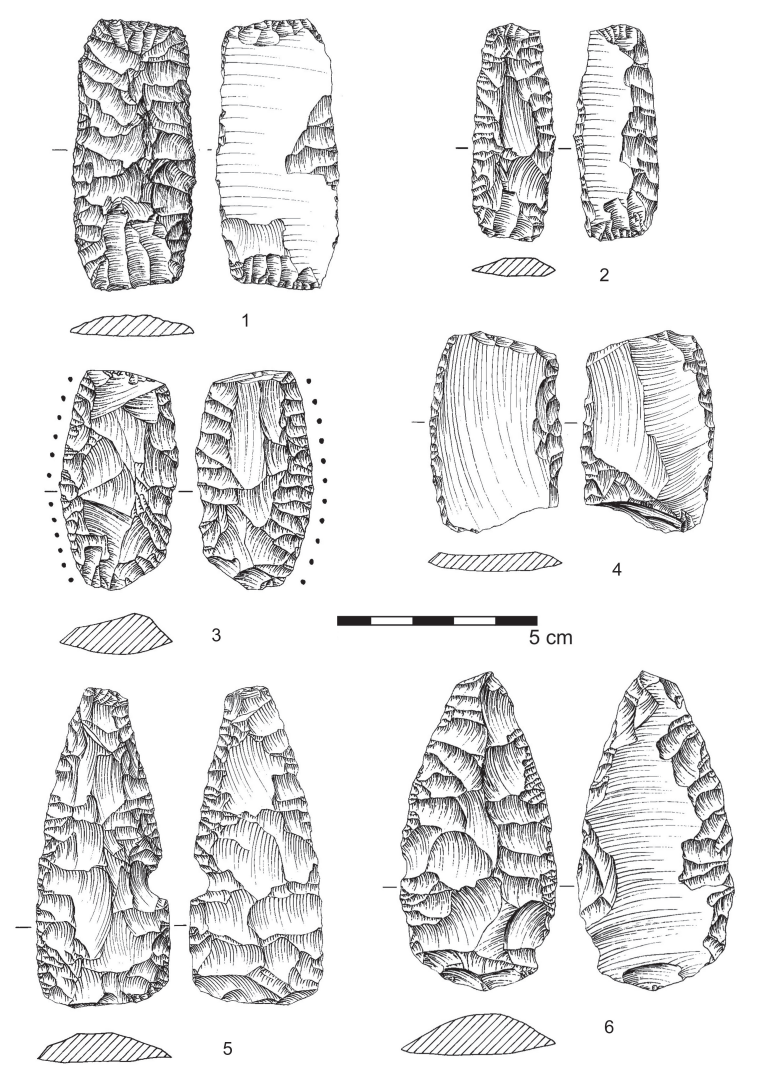

Fig. 7. Morfología de las láminas foliáceas del poblado de Leceia (Oeiras): sub-rectangular (1 del nivel 3; 2 del nivel 2); sub-trapezoidal (3 del nivel 2; 4 del nivel 2); apuntada (5 del nivel 3; 6 del nivel 2) (Cardoso y Martins 2013: 488, 489, 511, 517 y 518).

Trab. Prehist., 76, N. ${ }^{\circ}$ 2, julio-diciembre 2019, pp. 357-370, ISSN: 0082-5638

https://doi.org/10.3989/tp.2019.12243 


\begin{tabular}{|l|c|c|c|c|}
\hline Longitud & Nivel 4 & Nivel 3 & Nivel 2 & Total \\
\hline $111-120 \mathrm{~mm}$ & - & - & 1 & 1 \\
\hline $101-110 \mathrm{~mm}$ & - & - & 1 & 1 \\
\hline $91-100 \mathrm{~mm}$ & - & 1 & 2 & 3 \\
\hline $81-90 \mathrm{~mm}$ & - & 4 & 3 & 7 \\
\hline $71-80 \mathrm{~mm}$ & - & 7 & 14 & 21 \\
\hline $61-70 \mathrm{~mm}$ & 1 & 11 & 25 & 37 \\
\hline $51-60 \mathrm{~mm}$ & 1 & 7 & 17 & 25 \\
\hline $41-50 \mathrm{~mm}$ & 1 & 5 & 14 & 20 \\
\hline $30-40 \mathrm{~mm}$ & 2 & - & - & 2 \\
\hline TOTAL & 5 & 35 & 77 & 117 \\
\hline Anchura & Nivel 4 & Nivel 3 & Nivel 2 & Total \\
\hline $53-56 \mathrm{~mm}$ & - & - & 1 & 1 \\
\hline $49-52 \mathrm{~mm}$ & - & - & 1 & 1 \\
\hline $45-48 \mathrm{~mm}$ & - & - & 3 & 3 \\
\hline $41-44 \mathrm{~mm}$ & - & 1 & 3 & 4 \\
\hline $37-40 \mathrm{~mm}$ & - & 3 & 15 & 18 \\
\hline $33-36 \mathrm{~mm}$ & 2 & 9 & 24 & 35 \\
\hline $29-32 \mathrm{~mm}$ & 1 & 13 & 17 & 31 \\
\hline $25-28 \mathrm{~mm}$ & 1 & 4 & 8 & 13 \\
\hline $21-24 \mathrm{~mm}$ & - & 4 & 3 & 7 \\
\hline $17-20 \mathrm{~mm}$ & - & - & 2 & 2 \\
\hline $13-16 \mathrm{~mm}$ & 1 & 1 & - & 2 \\
\hline TOTAL & 5 & 35 & 77 & 117 \\
\hline
\end{tabular}

Tab. 4. Longitud y anchura de las láminas foliáceas plenamente configuradas del poblado de Leceia (Oeiras), respecto a su distribución estratigráfica y cronológica.

ra y la segunda línea defensiva. La importante presencia de núcleos y preformas se relaciona quizás con un espacio de talla en el interior del poblado, sin que sepamos si tales restos están vinculados exclusivamente con la producción de las láminas foliáceas. El sílex empleado procedería del cercano Monte do Castelo y Barotas (Cardoso y Costa 1992; Cardoso et al. 1996). La ausencia de lascas de dimensiones considerables nos lleva a proponer la realización de las primeras fases de configuración fuera del poblado, efectuándose en las zonas del interior las últimas fases de adelgazamiento y/o reavivado (Carvalho 1995-1996).

En el nivel 2 (Calcolítico Pleno/Final) las numerosas piezas foliáceas se concentran en zonas con funciones específicas: áreas de elaboración de láminas bifaciales, con centenares lascas de preparación halladas entre la primera y segunda línea defensiva, así como una cabaña especializada en la molienda donde se localizaron diversos molinos y manos (Fig. 2). Curiosamente, el porcentaje de esbozos es mucho menor en comparación con en comparación con el nivel 3. Las láminas foliáceas estarían directamente relacionadas con actividades productivas desarrolladas por los habitantes del poblado, ya que la mayor parte se concentran en los lugares que ocupaban las cabañas. Para la elaboración de estas piezas se recurría a variedades de sílex locales (Monte do Castelo y Barotas), y alóctonas (área de Rio Maior).

De nuevo la escasez de piezas en el nivel 4 ha impedido identificar alguna distribución espacial significativa.

\subsection{Análisis funcional sobre láminas foliáceas: un primer test}

Hemos realizado un análisis funcional exploratorio sobre 10 láminas foliáceas de los niveles 2 y 3 (el $3,5 \%$ de las documentadas). El objetivo principal ha sido evaluar si su estado de conservación permitía su estudio (Fig. 8). Sin embargo, los interesantes resulta-

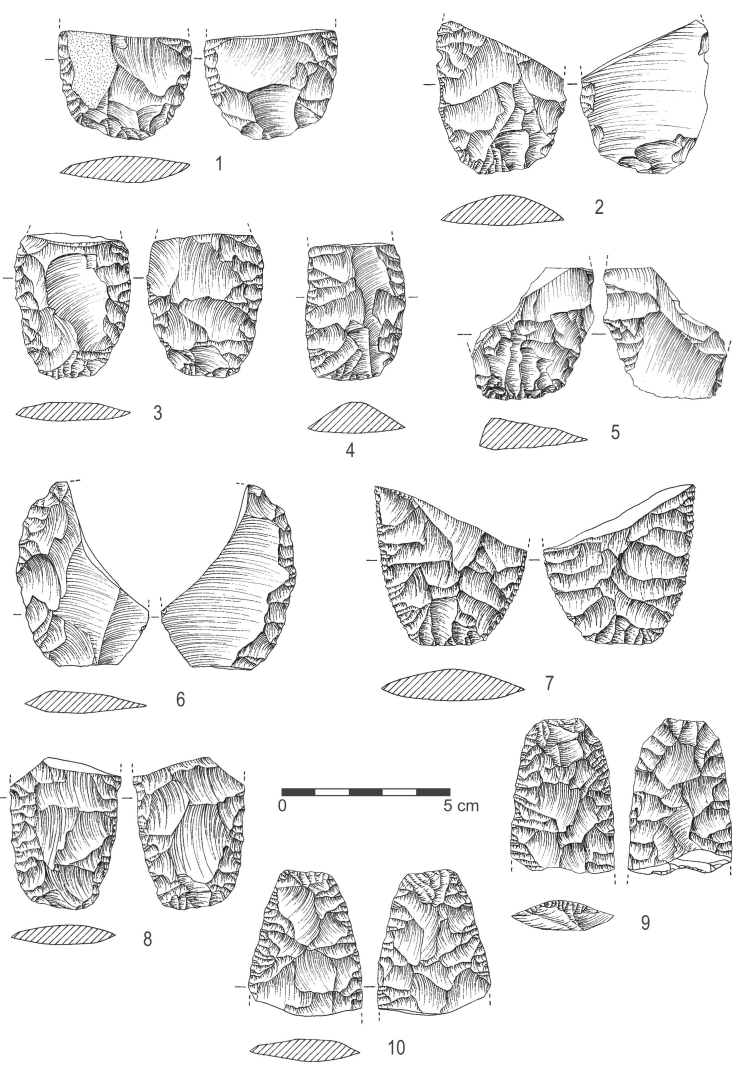

Fig. 8. Láminas foliáceas del poblado de Leceia (Oeiras) sobre las que se ha realizado el análisis funcional: 1 a 5 del nivel $3 ; 7$ a 10 del nivel 2 y 6 del nivel 3/2 (Cardoso y Martins 2013: 484-486, $489,512$ y $515-517)$. 
dos obtenidos y la posibilidad de explicar sus características y representatividad en un yacimiento tan relevante como Leceia, nos ha llevado a incluir la información en esta publicación.

Se seleccionaron piezas incompletas, susceptibles de haberse fracturado tanto durante su uso como durante su elaboración, dado que es este análisis debía permitirnos distinguir esbozos, piezas en elaboración e instrumentos usados y fracturados quizás durante su utilización.

El análisis macro y microscópico de la superficie nos ha confirmado que 7 de las 10 piezas estudiadas no presentan huellas de utilización, lo que nos ha permitido obtener información referida a los procesos de talla y a su configuración. Además, dos de ellas muestran un elemento interesante: una fuerte percusión en el centro de una de las caras (Fig. 9). Esa repetición nos sugiere que tal vez los talladores fracturaran estas piezas de manera intencional cuando el resultado no fuera satisfactorio. Deberemos retomar la cuestión en el futuro cuando analicemos otras piezas.

Las tres piezas usadas se han empleado para cortar cereales: dos con ambos laterales y una con un único filo. El grado de desarrollo de los pulidos es muy variable por los continuos procesos de reavivado para alargar la vida de las piezas (Fig. 9). En dichos filos se aprecia una cantidad variable de pulido de cereal acumulado en el interior de las melladuras. Ello se debe al momento del reavivado. Las primeras zonas reavivadas presentan pulidos más intensos y las últimas no lo están. Esto significa que, en ese momento, se rompió, abandonándose sin volver a usarse. Aunque no podemos saber el número de reavivados realizados, esa heterogeneidad en la cantidad de pulido demuestra que fueron varios.

El pulido de cereal de los filos usados muestra, en ocasiones, numerosas estrías, cuya presencia sugiere su empleo para segar los tallos cerca del suelo. Este hecho también se ha registrado en otros yacimientos cronológicamente próximos como el Casetón de la Era o Chibanes (Gibaja et al. 2012; Clemente et al. 2014).

La distribución del pulido de cereal no es homogénea a lo largo del filo, por lo que es imposible reconocer el modo de enmangue. En todo caso, ese pulido en las zonas mediales demuestra que buena parte del filo quedaba libre del mango. Precisamente, en la arista central de una de las piezas hemos reconocido un residuo negruzco que tal vez sean restos de la almáciga. Esta hipótesis deberá confirmarse mediante su análisis químico.

El uso de las láminas únicamente para segar es una cuestión que deberemos resolver estudiando un conjunto mayor. Quizás también se usaron para el trillado,
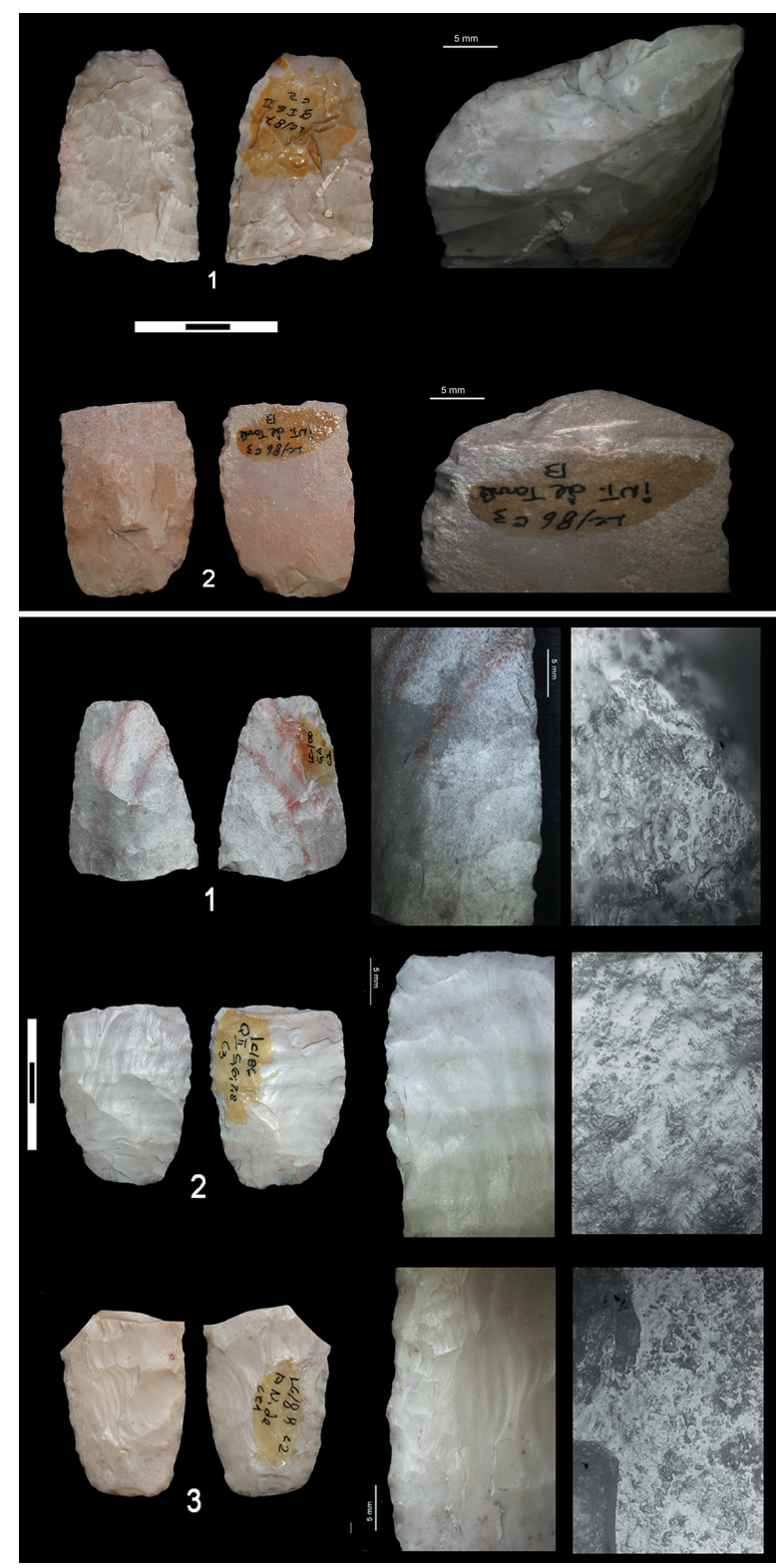

Fig. 9. Láminas foliáceas del poblado de Leceia (Oeiras). Arriba marcas de percusión en el centro (1 del nivel 2; 2 del nivel 3), producto tal vez de una rotura intencionada por parte del tallador. Abajo algunas usadas para segar cereales (1 y 3 del nivel 2; 2 del nivel 3) (en color en la versión electrónica).

documentado igualmente en los yacimientos de Casetón de la Era o Chibanes, o para el tratamiento de otras materias animales y vegetales. También será interesante analizar hasta qué punto su forma se relaciona con el trabajo realizado. 


\section{LAS LÁMINAS FOLIÁCEAS DE LECEIA VERSUS LAS DE OTROS POBLADOS DE LA ESTREMADURA PORTUGUESA}

Desde una perspectiva supraregional, se aprecia una concentración de este tipo de artefactos en la Península de Lisboa. Ello se explica, probablemente, por los afloramientos de sílex de buena calidad presentes en la zona de Rio Maior (Forenbaher 1998, 1999).

Estas piezas no han sido demasiado estudiadas en muchos otros yacimientos, pero es factible hacer un ensayo comparativo superficial con respecto a los de: Moita da Ladra (Vila Franca de Xira), Outeiro Redondo (Sesimbra), Penedo de Lexim (Mafra), Vila Nova de São Pedro (Azambuja) y Zambujal (Torres Vedras) (Cardoso 2014; Cardoso y Martins 2016-2017, 2018).

\subsection{Neolítico Final}

Hemos comparado las láminas foliáceas del nivel 4 de Leceia con las de la unidad estratigráfica UE19 (locus 1) del poblado de Penedo de Lexim (Mafra), adscrita al Neolítico Final (Sousa 2010; Cardoso 2013). En Leceia se han documentados 15 ejemplares, entre enteros y fragmentados $(6,9 \%$ del conjunto lítico del citado nivel). De éstas, 3 son esbozos, 7 están en una primera fase de preforma y 5 están enteras y aparentemente finalizadas para ser utilizadas. Predominan las láminas elipsoidales elaboradas mediante retoque cubriente bifacial, seguidas de unas en forma de " $D$ " y otras de morfología creciente. Como hemos apuntado la cantidad sería mayor si hubiera aumentado la zona excavada (Cardoso 2013).

En el poblado de Lexim se han contabilizado 60 ejemplares, sólo 10 enteros. Documentados en diversos sectores del asentamiento, 7 se han considerado productos relacionados con las primeras fases de preparación, 27 con los momentos de adelgazamiento, 17 son láminas acabadas y 9 no han podido adscribirse a ninguna de estas etapas (Sousa 2010). Morfológicamente dominan las piezas con bordes convergentes (24: $62 \%$ de las piezas clasificables), seguidas de las que tienen laterales paralelos con formas sub-rectangulares (9: $23 \%)$ $\mathrm{y}$ un conjunto de formas divergentes de formas trapezoidales $(15 \%)$. Las extremidades de la mayoría son rectilíneas (22 ejemplares), seguida de las convexas (10), oblicuas (5), triangulares (3) y apuntadas (4).

La información estratigráfica en relación a las láminas foliáceas es inexistente. La autora apunta, sin referencia a su morfología, que 5 pertenecen a la UE19 (locus 1) del Neolítico Final, 10 a la UE7 (locus 3b) del Calcolítico Inicial y 10 a la UE8 (locus 1) del Calcolítico Pleno/Final (Sousa 2010).

\subsection{Calcolítico Inicial}

Las 114 láminas foliáceas del Calcolítico Inicial del nivel 3 de Leceia superan considerablemente a las 24 piezas halladas en el nivel 3 de Outeiro Redondo (Sesimbra), y a las 10 de la UE7 (locus 3b) de Penedo do Lexim (Mafra) (Sousa 2010; Cardoso 2013; Cardoso y Martins 2016-2017, 2018).

En Leceia la representatividad de los esbozos y las piezas correspondientes a los primeros estadios de talla $(5: 4,4 \%)$ es mucho menor que la de las preformas (74: $64,9 \%$ ) y la de las piezas definitivamente acabadas (35: 30,7 \%). Sobresalen las elipsoidales (18: $51,4 \%$ ), seguidas de las que tienen una forma apuntada (8: $22,9 \%)$ y las tipo creciente $(4: 11,4 \%)$. Son anecdóticas las de forma en " $\mathrm{D}$ " (3: 8,6 \%), las láminas subrectangulares y las de contorno subtrapezoidal (1: 2,9\% en cada caso). Habitualmente las láminas tienen retoque bifacial cubriente, si bien algunas están retocadas de manera marginal o sólo por una cara.

De los 24 ejemplares de Outeiro Redondo, 8 están completas $(33,3 \%), 3$ son preformas $(12,5 \%)$ y el resto han sido adscritas simplemente a láminas fragmentadas por uno de los extremos $(54,2 \%)$. Como en Leceia, morfológicamente dominan las que tienen un contorno elipsoidal (6 ejemplares). Hay una en forma de "D" y otra apuntada.

La autora no hace ninguna referencia (Sousa 2010) a los 10 ejemplares de Penedo do Lexim, por lo que la comparación sólo se refiere a la cantidad.

\subsection{Calcolítico Pleno/Final}

De este momento se han valorado los datos del nivel 2 de Leceia del también nivel 2 de Outeiro Redondo (Sesimbra), del poblado de Moita da Ladra (Vila Franca de Xira) y de Penedo do Lexim (Mafra) (Sousa 2010; Cardoso 2013, 2014; Cardoso y Martins 20162017, 2018):

En las 159 láminas foliáceas de Leceia se vuelve a percibir la escasez de esbozos y primeros estadios de talla $(10=6,3 \%)$ frente a las preformas $(72=$ $45,3 \%)$ y las piezas acabadas $(77=48,4 \%)$. Morfológicamente dominan las de tipo elipsoidal, seguidas de las que tienen forma en "D". El resto presentan valores por debajo del $10 \%$.

Esta diversidad morfológica se aprecia igualmente en las 81 láminas foliáceas recuperadas en el poblado de Outeiro Redondo: 5 son esbozos, 41 son fragmentos de extremidades y 35 están plenamente configuradas. Nuevamente dominan las elipsoidales, seguidas de las que tienen forma de "D", las subrectangulares y subtrapezoidales. 
En el poblado de Moita da Ladra se recogieron 4 esbozos, 25 preformas y 6 piezas acabadas y sin fracturar. Sobresalen las de contorno elipsoidal $(33,3 \%)$ y las de forma en "D" (33,3\%), seguidas de las tipo creciente $(16,7 \%)$ y las apuntadas $(16,7 \%)$.

Las 10 láminas foliáceas de Penedo do Lexim, provenientes de la unidad estratigráfica EU 8 (locus 1), representan el $9 \%$ del utillaje lítico registrado en este nivel. Desafortunadamente, la autora amplía su descripción (Sousa 2010).

La abundante presencia de esbozos y piezas fragmentadas en los poblados comparados permite concluir la intensa preparación y elaboración de láminas bifaciales en todos ellos. Parece existir un patrón morfológico mayoritario elipsoidal y en forma de " $D$ ". El resto muestra porcentajes variables, habitualmente por debajo del $12 \%$. Si bien son difíciles lecturas más precisas al faltar estudios tecno-tipológicos profundos, esta visión superficial puede ayudar al lector a comprender la naturaleza de este tipo de piezas en otros contextos lusos.

\subsection{Otras referencias}

La información disponible de los poblados calcolíticos de Vila Nova de São Pedro (Azambuja), Zambujal (Torres Vedras) y Pedrão (Setúbal) es aun más muy reducida pero nos ha parecido interesante aludir brevemente a ellos.

De los 3586 restos líticos inventariados en Vila Nova de São Pedro, 387 son láminas foliáceas ${ }^{3}$. En las intervenciones de 1964 a 1973 realizadas en el poblado de Zambujal se contabilizaron cerca de 2400 artefactos de los cuales $20(0,8 \%)$ eran útiles subrectangulares u ovales con retoque plano unifacial considerados "cuchillos de lasca", 70 (2,9\%) fueron catalogados como "cuchillos en fase de transición" y 176 (7,3 \%) como "cuchillos foliáceos" adelgazados mediante retoques planos) (Uerpmann y Uerpmann 2003).

En términos estratigráficos parece que predominan los "cuchillos de lasca" en las fases constructivas 1 y 2 (precampaniformes) y las láminas acabadas y retocadas por ambos laterales en las fases 3 a 5 (Uerpmann y Uerpmann 2003).

En el asentamiento del Calcolítico Inicial de Pedrão, de los 132 restos líticos hallados sólo 5 son láminas foliáceas fracturadas. Tres presentan un retoque invasor bifacial y las otras dos unifacial (Soares y Silva 1975).

\footnotetext{
${ }^{3}$ P. M. A. Rebelo. A Indústria em pedra lascada no povoado Calcolítico de Vila Nova de São Pedro - Azambuja. Trabajo de Master Inédito, Universidade do Algarve, 2012.
}

\section{RECAPITULACIÓN}

Hemos dedicado este trabajo a la caracterización tecno-morfológica de las piezas conocidas como foicinhas o "láminas foliáceas" (Cardoso y Martins 2013). En el asentamiento de Leceia, el sílex empleado en su elaboración es originario de diversos afloramientos, algunos cercanos, como el del Monte do Castelo y Barotas, y otros alejados, como el de Rio Maior. Ello nos hace pensar en la complejidad de las relaciones sociales que debieron existir en aquella época y que se tradujeron en la posibilidad de acceder a determinadas materias primas. La obtención de un tipo de sílex de óptima calidad era básica para lograr piezas excelentemente talladas. Precisamente, el tratamiento térmico podría ser un recurso que facilitara la talla y redujera la posibilidad de errores.

La ausencia de soportes en bruto nos hace suponer que las primeras etapas de elaboración se realizaban fuera del poblado. Serían los procesos de adelgazamiento y reavivado los que finalmente serían llevados a cabo en la zona de intramuros. Ello refleja la alta capacidad tecnológica de algunos habitantes de Leceia. Tampoco debemos excluir que algunos soportes llegaran ya ligeramente preparados al poblado, especialmente los confeccionados a partir de las variedades de sílex procedentes de la región de Rio Maior. La representatividad porcentual de tales láminas es muy distinta según los niveles: en el nivel 4 suponen el 6,9\% del utillaje lítico, en el 3 llegan al 26,7\% y en el 2 al $31,6 \%$. Su importancia en este último, adscrito al Calcolítico Inicial, puede estar vinculada con el aumento de las actividades productivas agrícolas. En los niveles 3 y 2 las láminas tienen retoque cubriente bifacial y contorno elipsoidal. A lo largo de la secuencia parece aumentar la longitud y anchura de estas piezas, superando a veces los $100 \mathrm{~mm}$ de longitud y los 40 $\mathrm{mm}$ de anchura.

En definitiva, este trabajo viene a sumarse a los que, de una manera más o menos amplia y precisa, han tratado la tecnología y la morfología lítica de este tipo de piezas (Jalhay 1947; Soares y Silva 1975; Serrão 1978; Zilhão 1994; Carvalho 1995-1996; Forenbaher 1999; Uerpmann y Uerpmann 2003; Sousa 2010; ; Cardoso 2013; Cardoso y Martins 2013, 2016-2017, 2018).

Los resultados del análisis funcional, a la espera de un estudio más completo, nos permiten proponer el uso de muchas de estas las láminas foliáceas. Sin embargo, no es menos cierto que al ser un lugar de producción muchas de esas láminas se fracturaron y abandonaron durante su elaboración. Las tres piezas

\footnotetext{
${ }^{4}$ Véase n. 3.
}

Trab. Prehist., 76, N. ${ }^{\circ} 2$, julio-diciembre 2019, pp. 357-370, ISSN: 0082-5638

https://doi.org/10.3989/tp.2019.12243 
con huellas de uso se vinculan con el trabajo de la siega y no tanto con el de trillado, como se ha observado en Casetón de la Era o Chibanes (Gibaja et al. 2012; Díaz del Río et al. 2014; Clemente et al. 2014). El muestreo ha sido escaso, pero todo indica que el uso del término foicinhas, acuñado desde la arqueología portuguesa, no iba mal encaminado. En el futuro será interesante, no sólo analizar un mayor número de piezas de Leceia, sino de otros yacimientos. De esta manera podremos evaluar su funcionalidad en base a distintos parámetros: actividades realizadas en los asentamientos, cronología, lugares de trabajo, acceso a materias primas de calidad, etc.

Pero, además, será importante estudiar el uso de otro tipo de instrumentos líticos con el fin de caracterizar la producción global. Tal vez ese análisis de conjunto nos permita conocer mejor los criterios que rigieron la selección de ciertas morfologías en relación a las actividades a las que se iban a destinar los instrumentos. Es evidente que nos queda mucho por hacer, pero consideramos que los resultados aquí expuestos son un primer paso en el estudio de unos instrumentos bastante olvidados por la investigación arqueológica pero enormemente relevantes para las comunidades del pasado.

\section{AGRADECIMIENTOS}

El Dr. Filipe Martins nos ayudó en la elaboración de este artículo, incluyendo el dibujo de las piezas líticas que lo ilustran. Reconocemos el gran trabajo de los dos revisores anónimos que han mejorado enormemente este artículo.

\section{BIBLIOGRAFÍA}

Blasco, C.; Delibes, G.; Baena, J.; Liesau, C. y Ríos, P. 2007: “El poblado calcolítico de Camino de las Yeseras (San Fernando de Henares, Madrid): un escenario favorable para el estudio de la incidencia campaniforme en el Interior Peninsular". Trabajos de Prehistoria 64 (1): 151-163. https://doi.org/10.3989/tp.2007.v64.i1.99

Cabanilles, J. J. 2008: El utillaje de piedra tallada en la Prehistoria reciente valenciana. Aspectos tipológicos, estilísticos y evolutivos. Servicio de Investigación Prehistórica del Museo de Prehistoria de Valencia. Valencia.

Cardoso, J. L. 1997: O povoado de Leceia, sentinela do Tejo no terceiro milénio antes de Cristo. Lisboa/Oeiras. Museu Nacional de Arqueologia, Câmara Municipal de Oeiras. Oeiras.

Cardoso, J. L. 2000: "The fortified site of Leceia (Oeiras) in the context of the Chalcolithic in Portuguese Estremadura". Oxford Journal of Archaeology 19 (1): 37-55. https://doi.org/10.1111/1468-0092.00098

Cardoso, J. L. 2003: O povoado pré-histórico de Leceia no quadro da investigação, recuperação e valorização do património arqueológico português. Síntese de vinte anos de escavações arqueológicas (19832002). Câmara Municipal de Oeiras. Oeiras.

Cardoso, J. L. 2004: A Baixa Estremadura dos finais do IV milénio a.C. até à chegada dos Romanos: um ensaio de História Regional. Es- tudos Arqueológicos de Oeiras 12. Câmara Municipal de Oeiras. Oeiras.

Cardoso, J. L. 2008: "The chalcolithic fortified site of Leceia (Oeiras, Portugal)". Verdolay 11: 49-66.

Cardoso, J. L. 2010: "Povoado pré-histórico de Leceia (Oeiras): evolução arquitectónica do sistema defensivo e das técnicas construtivas correlativas". Transformação e Mudança no centro e sul de Portugal: o $4 .^{\circ}$ e o $3 .^{\circ}$ milénios a.n.e. Colóquio Internacional (Cascais 2005): 43-63. Cascais.

Cardoso, J. L. 2011: "The prehistoric settlement of Leceia (Oeiras, Portugal). Results of the excavations of 1983-2002". Archaeological Journal Sup. 1: 42-51. https://doi.org/10.1080/00665983.2011.11020907

Cardoso, J. L. 2013: "O povoado calcolítico fortificado do Outeiro Redondo (Sesimbra). Resultados da primeira fase de escavações arqueológicas (2005-2008)". Estudos Arqueológicos de Oeiras 20: 641-730.

Cardoso, J. L. 2014: "O povoado calcolítico fortificado da Moita da Ladra (Vila Franca de Xira, Lisboa). Resultados das escavações efectuadas (2003-2006)". Estudos Arqueológicos de Oeiras 21: 217-294.

Cardoso, J. L.; Andrade, M. y Martins, F. 2018: "Sobre a presença de lâminas de sílex oolítico (e outras matérias-primas exógenas) no povoado calcolítico do Outeiro Redondo (Sesimbra, Portugal): interacção durante o $3 .^{\circ}$ milénio a.C. no sudoeste peninsular". Estudos Arqueológicos de Oeiras 24: 307-366.

Cardoso, J. L. y Costa, J. L. B. 1992: "Estação pré-histórica de Barotas (Oeiras)". Setúbal Arqueológica 9-10: 229-245.

Cardoso, J. L. y Detry, C. 2001-2002: "Estudo arqueozoológico dos restos de ungulados do povoado pré-histórico de Leceia (Oeiras)". Estudos Arqueológicos de Oeiras 10: 131-182.

Cardoso, J. L. y Martins, F. 2013: "O povoado pré-histórico de Leceia (Oeiras). Estudo dos utensílios de pedra lascada”. Estudos Arqueológicos de Oeiras 20: 357-524.

Cardoso, J. L. y Martins, F. 2016-2017: “O povoado pré-histórico do Outeiro Redondo (Sesimbra): Resultados das campanhas de escavação de 2013 e 2014". Estudos Arqueológicos de Oeiras 23: 233392.

Cardoso, J. L. y Martins, F. 2018: "Resultados das campanhas de escavação realizadas em 2015 e 2016 no Povoado Calcolítico do Outeiro Redondo (Sesimbra)". Estudos Arqueológicos de Oeiras 24: 181290.

Cardoso, J. L.; Norton, J. y Carreira, J. R. 1996: “Ocupação calcolítica do Monte do Castelo (Leceia, Oeiras)”. Estudos Arqueológicos de Oeiras 6: 287-299.

Carvalho, A. F. 1995-1996: "O talhe da pedra e a transição NeolíticoCalcolítico no Centro e Sul de Portugal: tecnología e aspectos da organização da produção". Trabalhos de Arqueologia da EAM (EStudo Arqueológico da Bacia do Mondego) 3-4: 41-60.

Clemente, I.; Mazzucco, N. y Soares, J. 2014: "Instrumentos para siega y procesado de plantas desde el Calcolítico al Bronce antiguo de Chibanes (Palmela, Portugal)". Trabajos de Prehistoria 71 (2): 330 342. https://doi.org/10.3989/tp.2014.12137

Díaz del Río, P.; Gibaja, J. F. y Castañeda, N. 2014: “Tecnología y funcionalidad del cuchillo calcolítico de la cabaña de 'El Capricho' (Barajas, Madrid)". Novenas Jornadas de Patrimonio Arqueológico en la Comunidad de Madrid (Madrid 2012): 367-371. Madrid.

Esteve, X.; Armentano, N.; Espejo, J. M.; Gallart, J.; Gibaja, J. F.; López, D.... y Vila, S. 2015: "El Pla de Tabac I (Montoliu de Lleida), un assentament de l'edat del bronze a la Plana de Lleida". Revista d'Arqueologia de Ponent 25: 137-168.

Forenbaher, S. 1998: "Production and exchange during the Portuguese Chalcolitic: the case of bifacial flaked stone industries". Trabajos de Prehistoria 55 (2): 55-71. https://doi.org/10.3989/tp.1998.v55.i2.303

Forenbaher, S. 1999: Production and exchange of bifacial stone artifacts during the Portuguese Chalcolithic. British Archaeological Reports, International Series 756, Archaeopress. Oxford.

Gibaja, J. F. 1999: “Análisis del registro lítico de 'El Recuenco' (Cervera del Llano, Cuenca)". Archivo de Prehistoria Levantina 23: $197-$ 208.

Gibaja, J. F. 2002: “Análisis funcional del registro lítico de Fuente Álamo (Almería)". En R. Risch (ed.): Recursos naturales, medios de producción y explotación social. Un análisis económico de la indus- 
tria lítica de Fuente Álamo (Almería) 2250-1400 ANE. Verlag Philipp von Zabern. Mainz: 163-177.

Gibaja, J. F.; Crespo, M.; Delibes, G.; Fernández, J.; Fraile, C.; Herrán, J. I.... y Rodríguez, J. A. 2012: "El uso de trillos durante la Edad del Cobre en la Meseta española. Análisis traceológico de una colección de denticulados de sílex procedentes del 'recinto de fosos' de El Casetón de la Era (Villalba de los Alcores, Valladolid)". Trabajos de Prehistoria 69 (1): 133-148. https://doi.org/10.3989/tp.2012.12084

Gibaja, J. F.; Palomo, T.; Terradas, X. y Clop, X. 2004: "Útiles de siega en contextos funerarios del 3500-1500 cal ANE en el Noreste de la Península Ibérica: el caso de las grandes láminas de sílex". Cypsela 15: $187-195$

Jalhay, E. 1947: "A alabarda de sílex do Casal da Barba Pouca (Mação) es a expansão das lanças e alabardas líticas em Portugal”. Brotéria XLIV: 35-56.

Mangado, J.; Vaquer, J.; Gibaja, J. F.; Oms, X.; Cebrià, A.; González, C. B.... y Marín, D. 2016: "New data concerning 'large blades' in Catalonia: Apt Forcalquier chert in the Penedès (south of Barcelona) during the Late Neolithic-Chalcolithic". Journal of Lithic Studies 4: 67-93. https://doi.org/10.2218/jls.v3i2.1833

Marín, D.; Gibaja, J. F.; Alonso, N.; Ortega, D.; Palomo, A. y Moya, A. 2017: "Chipped stone tools from the Early Bronze Age settlement of Minferri (2100-1650 cal. BC) (Lleida, Spain): Raw materials, technology and activities inferred". En A. Brysbaert y A. Gorgues (eds.): Artisans versus nobility? Multiple identities of elites and 'com- moners' viewed through the lens of crafting from the Chalcolithic to the Iron Ages in Europe and the Mediterranean. Sidestone Press. Leiden: $139-159$.

Paço, A. do y Jalhay, E. 1945: "El castro de Vilanova de San Pedro". Memorias de la Sociedad Española de Antropología, Etnografia y Prehistoria 20: 5-93.

Palomo, A.; Gibaja, J. F.; Ortega, D.; Alonso, N.; Marín, D. y Moya, A. 2012: "La industria lítica tallada del asentamiento de Minferri (Juneda, Lleida) a finales del III/primera mitad del II milenio cal. BC". Cypsela 19: 103-122.

Serrão, E. C. 1978: "Limitações do método comparativo na interpretação funcional dos testemunhos arqueológicos. Alguns exemplos". III Jornadas Arqueológicas I. Associação dos Arqueólogos Portugueses: 13-32.

Soares, J. y Silva, C. T. da 1975: “A ocupação pré-histórica do Pedrão e o Calcolítico da região de Setubal". Setúbal Arqueológica 1: 53153.

Terradas, X. y Gibaja, J. F. 2001: "E1 tratamiento térmico en la producción lítica: el ejemplo del Neolítico medio catalán". Cypsela 13: 29-56.

Uerpmann, H. P. y Uerpmann, M. 2003: Zambujal, Die stein- und Beinartefakte aus den Grabungen 1964 bis 1973. Madrider Beiträge 5, Verlag Philipp von Zabern. Mainz.

Zilhão, J. 1994: "A oficina de talhe neo-calcolítica de Casas de Baixo (Caxarias, Vila Nova de Ourém)". Trabalhos de Arqueologia da EAM Estudo Arqueologico da Bacia de Mondego) 2: 35-46. 